\title{
A Critical Overview of Research Studies on the Role of Positive Psychology Interventions in Enhancing Subjective Well-Being among High School Students
}

\author{
Jayashree Sanghani $^{1}$, Saroj Arya ${ }^{2}$
}

\section{ABSTRACT}

In the present educational system, students face a lot of pressure, stress and expectation from self and others which leads to experiencing negative emotions. These factors hinder children's all round development and scholastic achievement leading to low subjective well-being and poor life satisfaction. Hence, there is a need to foster positive emotions. A critical overview has been done on the role of Positive Psychology Interventions in enhancing positive emotions of the students in experiencing well-being, and satisfaction. School psychology has been focusing on addressing the problem and providing solutions. Experiencing positive emotions is more important for accomplishment and well-being than the absence of negative emotions. The essence of Positive Psychology Interventions is to remove what is wrong and bring in what is strong, by fostering positive factors important for flourishing and accomplishment. Research has shown that Positive Psychology Interventions are significantly related to student well-being which can augment life satisfaction.

Keywords: Subjective Wellbeing, Positive Psychology Interventions, Life Satisfaction

Adolescence is a critical period in personality development. Schools play an important role in assisting youth to develop cognitive, social and emotional skills. It is absolutely essential for the school curriculum to include the broader aspects of human development (Walters L,2011). There is a need to develop the skills of resilience, creativity and persistence (O' Brien \& Larson, 2008). As such, decisions have been made for schools to adopt a new paradigm of education for the 21st century (Fielding, 2001; Jackson \& Davis, 2000; MacDonald \& Hursh, 2006; Yates, 2007).

\footnotetext{
${ }^{1}$ Research Scholar, Mewar University, India

${ }^{2}$ Guide Mewar University, India

*Responding Author

(C) 2016 I J Sanghani, S Arya; licensee IJIP. This is an Open Access Research distributed under the terms of the Creative Commons Attribution License (http://creativecommons.org/licenses/by/2.0), which permits unrestricted use, distribution, and reproduction in any Medium, provided the original work is properly cited.
} 


\section{A Critical Overview of Research Studies on the Role of Positive Psychology Interventions in Enhancing Subjective Well-Being among High School Students}

The school curriculum presently in India is primarily focused on the completion of the portions for the year and the emphasis is on achieving better grades and competing with each other instead of discovering and honing capabilities and strengths of the children. The concept of children gaining better results must change to them receiving satisfying ones (Shwartz, 2004). People who are satisfied are less worried about regret, more optimistic, happier, less neurotic and less depressed than people who are not satisfied.

The prevalence of low well being and high depression among young people is shockingly high worldwide. Nearly $20 \%$ of them experience an episode of clinical depression by the end of high school (Lewinsohn et al, 1993). A systematic review and meta-analysis of Prevalence of Child and Adolescent Psychiatry disorders in India reveals the prevalence of $6.4 \%$ in community sample and 23.33\% in school samples (Malhotra \& Patra, 2014), subject to various reasons like academic stress and dissatisfaction, peer pressure, poor family relationship leading to high level and frequency of negative emotions leading to low subjective well being. The prevailing situation lays a foundation for generating positive emotions among school children through Positive Psychology Intervention.

\section{Positive Psychology}

Positive Psychology is defined as the scientific study of well-being and optimal human functioning (Gable \& Haidt, 2005). Since a seminal article by Seligman and Csikszentmihalyi (2000) called for a renewed focus within the social sciences on positive aspects of human functioning, the field has grown rapidly and is now established as a credible and ever-evolving field of research and practice (Rusk \& Waters, 2013).

The emphasis of positive psychology is on strengths and virtues and to shift focus from solely on psychological deficits to a balance of remediation of difficulties and proactive building of strengths and qualities (Seligman \& Csikszentmihalyi,2000).

The theoretical underpinnings of positive psychology stem from the work of Seligman (2002), who has proposed that happiness consists of the pleasant life, the engaged life and the meaningful life. The pleasant life is achieved when people are able to experience positive emotions about their past, present and future lives. The engaged life is felt when one is deeply involved and absorbed in what one is doing in multiple life roles, including love, work, and play. The meaningful and flourishing life is defined as using one's strengths in the service of something larger than oneself (Seligman, 2002).

\section{Subjective Well- Being}

The scientific construct of subjective well- being comprises of both cognitive and affective self evaluation of one's life and experiences (Diener 1994). 


\section{A Critical Overview of Research Studies on the Role of Positive Psychology Interventions in Enhancing Subjective Well-Being among High School Students}

Subjective well-being is a broad concept that includes experiencing pleasant emotions, low levels of negative moods and high life satisfaction. It is comprised of three separate but related constructs, specifically frequency of positive affect, frequency of negative affect, and level of life satisfaction. Life satisfaction - Diener (1994) defined global life satisfaction (LS) as a person's cognitive judgement of his or her satisfaction with life on the whole. Positive affect - Diener (1994) defined positive affect (PA) as situationally bound positive emotion (e.g., positive mood characterized by interest, engagement, and energy). Negative affect - Diener (1994) defined negative affect (NA) as situationally bound negative emotions (e.g., negative mood such as fear, sadness and anger).

\section{Life Satisfaction}

Global Life Satisfaction (GLS) is a person's cognitive judgement of his or her satisfaction with life as a whole (Diener., 1994)

During childhood and adolescence, academic achievement is important because in today's society, academic accomplishments as well as failures determine an individual's future academic career and job opportunities (Kadison and DiGeronimo, 2004; Rana and Mahmood, 2010). Several studies were evaluated and published several by Fordyce $(1977,1983)$ that suggested, happiness can be boosted by Positive Psychology Interventions(PPI).

Individual's performance reflects life satisfaction across life domains.( Life Satisfaction and Students Performance). Rode et al., posited that life satisfaction has both stastistical and practical significance to students' performance .

Longitudinal studies provide evidence that the correlation between academic performance and life satisfaction might be reciprocal i.e., high achievement score may increase life satisfaction which eventually motivates students to get better grades. (Samdal et.al).

A study conducted across nations reported that the experience of positive emotions was more strongly related to life satisfaction than the absence of negative emotions (Kuppens, Peter; Realo,Anu; Diener,Ed, 2008).

Positive emotions predicted increase in both resilience and life satisfaction. Negative emotions had weak or null effects, and did not interfere with the benefits of positive emotions. (Cohn, Michael et al, 2009)

\section{Affect/Emotions}

Affect is the term psychologists use to describe a person's experience of his or her emotions. Typically, emotions begin with an individual's assessment of the personal meaning of some

(C) The International Journal of Indian Psychology, ISSN 2348-5396 (e)| ISSN: 2349-3429 (p) | 184 


\section{A Critical Overview of Research Studies on the Role of Positive Psychology Interventions in Enhancing Subjective Well-Being among High School Students}

antecedent event. Lazarus (1991) called this as personal environment, relationship, or adaptation encounter. Measures of affect can be thought of as measures of particular feelings or emotional states, and they are typically measured with reference to a particular point in time. Such measures capture how people experience life rather than how they remember it (Kahneman and Krueger, 2006). While an overall evaluation of life can be captured in a single measure, affect has at least two distinct hedonic dimensions: positive affect and negative affect (Kahneman et al., 1999; Diener et al., 1999). Positive affect captures positive emotions such as the experience of happiness, joy and contentment. Negative affect, on the other hand, comprises the experience of unpleasant emotional states such as sadness, anger, fear and anxiety.

This appraisal process either conscious or unconscious triggers a cascade of response tendencies which are manifested across loosely coupled component system, such as subjective experience, facial expressions, and physiological changes i.e., specific action tendencies and physiological changes are supplementary in nature.

1. Negative mental state. Negative mental state is less than neutral, experiencing hate, anger, jealousy and sadness.

The key to emotions are associated with specific action tendencies (Frijda, 1986; Frijda et al., 1989). For example, fear is linked with the urge to escape, anger with the urge to attack, disgust with the urge to expel. (Fredrickson, 2004)

Negative emotions when extreme, prolonged or contextually inappropriate produce many grave problems for individuals and society ranging from phobias and anxiety disorders, aggression and violence, depression and suicide, eating disorders and sexual dysfunction to a host of stress related physical disorders.

Research studies on the effect of negative emotions. Frequent experiences of negative emotions arise from lack of self satisfaction with academic achievements, negative peer pressure, physical punishment, teasing and bullying at school. These factors were significantly associated with depression that was found in students irrespective of the Board they belonged to, streams that they have chosen or their socio economic status as reported by Nirmal Verma, after a research conducted on three hundred and twenty one students studying in various boards of education in Raipur, India. The aim of the study was to assess the prevalence of depression among school students. The results had shown that $40.49 \%$ were found to be mildly depressed \& $19 \%$ had suffered from major depression and the corresponding factors were academic dissatisfaction, peer pressure, and poor family relationships (Verma, Jain, \& Roy, 2014).

(c) The International Journal of Indian Psychology, ISSN 2348-5396 (e)| ISSN: 2349-3429 (p) | 185 


\section{A Critical Overview of Research Studies on the Role of Positive Psychology Interventions in Enhancing Subjective Well-Being among High School Students}

The negative rumination may be one of the reasons that students with low hope experience more anxiety and are more likely to be side tracked by self derogatory thoughts while taking the test (Onwuegbuzie \& Snyder, 2000) which was proved by the study.

To examine the relationship between academic stress and depression among adolescents, a crosssectional study was conducted in higher secondary school in Tamil Nadu, India which found that 1,224 students out of 2,432 tested were suffering from mild to moderate depression. Further investigation by Beck Depression Inventory (BDI) showed that out of the Cases Involved (CI), those with academic stress were at 2.4 times $(95 \% \mathrm{CI}=0.924)(\mathrm{P}<0.001)$ at higher risk of clinical depression than those without academic stress.

Fear limits cognitive processing and generally amplifies our human tendencies to avoid taking action when positive emotions are in short supply (Fredrickson, 2004).

Over centuries, Psychology has been focusing on generating a remedy for the problem or dissolution of problem behaviour and bridging the deficit. Whereas, Positive Psychology, with a changed perspective, establishes the positive and the strengths, and emphasizes on developing them. As such, understanding positive affect or positive emotions becomes vital.

2. Positive mental state. Positive mental state is more than neutral when individuals experience joy, interest contentment and love. Free floating positive emotions motivate individuals to continue along any line of thinking or action that they have initiated. Positive emotion of joy sparks the urge to play, interest urges to explore, contentment sparks the urge to savour and integrate, love sparks a recurring cycle of these urges within safe and close relationships.

Research Studies on Effect of Positive Emotions: Positive emotions broaden through action repertoires. The work of Khan \& Isen shows that experiencing positive affect increases preference for variety and acceptance of a broader array of behavioural options. Fredrickson \& Branigan (2005) conducted an experimental study and found that participants in two positive emotional states of Joy and Contentment will do the right thing, more than those in the negative emotional state of fear and anger.

2.1. Positive emotions undo lingering negative emotions. The undo hypothesis states that positive emotions may 'correct' or 'undo' the after effects of negative emotions. Earlier work on anxiety disorders has demonstrated the basic observation that positive and negative emotions are somehow incompatible. However, the precise mechanism responsible for this incompatibility has not been identified. The broaden function of positive emotions may play a role, by broadening an individual's momentary thought - action repertoire. This would result in the positive emotion loosening the hold of the negative emotion on the individual. One marker of the specific action tendencies associated with negative emotions is increased cardiovascular activities. Fredrickson

(C) The International Journal of Indian Psychology, ISSN 2348-5396 (e)| ISSN: 2349-3429 (p) | 186 


\section{A Critical Overview of Research Studies on the Role of Positive Psychology Interventions in Enhancing Subjective Well-Being among High School Students}

and Branigan (2005) tested this hypothesis and found two distinct types of positive emotions mild joy and contentment - that share the ability to undo the lingering cardiovascular after effects of emotions.

2.2. Positive emotions fuel psychological resiliency. Resilience is the capacity to pull through after an adversity which suggests that resilient individuals would exhibit faster cardiovascular recovery following a high-activation negative emotion than less resilient individuals. Tugade \& Fredrickson (2004) tested this hypothesis and found that resilient participants took less time to achieve cardiovascular recovery and was accounted for by differences in positive emotions. A prospective field study of American College Students before and after the terrorist attacks of September 11, 2001 provided consistent evidence.

Studies (Block \& Kremen, 1996; Klohnen, 1946) have shown evidence that suggests that resilient people have optimistic, zestful and energetic approach to life, are curious and open to new experiences and are characterized by high positive emotions. Resilient people have been found to use positive emotion of humour (Werner \& Smith, 1992), creative exploration (Cohler, 1987), relaxation and optimistic thinking (Murphy \& Moriarty, 1976; Anthony, 1987) as strategies of coping ie., Ability to cultivate one or more positive emotions such as amusement, interest, contentment or hope respectively.

2.3. Positive emotions build personal resources. Evidence suggests that positive emotions may fuel individual differences in resilience. This hypothesis was tested by B.L. Fredikon in 2004 found that participants who found positive meaning and purpose in their best, worst and seemingly ordinary experiences each day showed increased resilience than those who did not find any positive meaning in their daily life experiences. This is a comment on how people might begin to harness the beneficial effects of positive emotions to optimize their own well being.

Positive Emotions fuel Psychological and Physical Well Being. The relationship between positive meaning and positive emotion is considered reciprocal i.e., finding positive meaning not only triggers positive emotions but also they broaden thinking and increases the likelihood of finding positive meaning in subsequent events (Fredikson, 2004). This in turn builds people's psychological resilience and leads to enhanced subjective well being. It strengthens upward spiral and breaks the downward spiral created during depression. This was tested by Fredrikson \& Joiner (2002) and result suggested that positive emotions and broad minded coping mutually depend on one another: Positive emotion not only makes one feel good in the present, but also by broadening thinking and building resources increase the likelihood of doing good and feeling good in future. 


\section{A Critical Overview of Research Studies on the Role of Positive Psychology Interventions in Enhancing Subjective Well-Being among High School Students}

Williams and Shaw (1999) posited that happier people have shown to be more co-operative, charitable and pro-social. Happy individuals were more likely to self regulate and cope with adversities and have healthier immune function

\section{Positive Psychology Interventions (PPI)}

They are characterised as "Programs, practices, treatment methods, or activities aimed at cultivating positive feelings, cognition, and behaviour. (Sin \& Lyu bomirsky, 2009). PERMA Model suggests that PPIs focus on Positive Emotions, Positive Engagement, Positive Relationships, Meaning, and Accomplishment (Seligman 2011). The removal of what is wrong and bring in what is strong is the essence of Positive Psychology Intervention; it seeks to 'add' rather than replace the approaches to well being that aim to reduce negative factors (Waters, 2011).

Being engaged involves a high life interest. As schools play an increasingly important role in assisting youth to develop cognitive, emotional, and social skills, it becomes ideal to introduce PPI in school curriculum so that students get equipped with absorbing activities and are engaged leading to flourishing accomplishment.

\section{Research studies on positive psychology interventions.}

1. Positive psychology intervention cultivates hope among students. Synder (1995) defined Hope as "the process of thinking about one's goal, along with motivation to move towards goals (agency) \& the way to achieve those goals (pathways). The study observes the relationship between hope and graduate students studying and test taking strategies by on Wegbujjie \& Sysnder (2000), found that high hope is positively correlated to higher scores. Students with hope showed better problem solving abilities and they used fewer disengagement strategies when dealing with stressful academic situations.

Marques, Lopez \& Pais- Ribeiro (2011) investigated the effectiveness of a five week hope base intervention with the middle school students by a control group and an intervention group. Post test results showed that intervention group had significantly enhanced levels of hope, life satisfaction and self worth. They posited that a brief hope intervention delivered at school can increase well-being and that these benefits are long lasting.

2. Positive psychology intervention cultivates gratitude among students. Gratitude is defined as "a sense of joyful thankfulness in response to receiving a gift, whether the gift is a tangible benefit from a specific other or a moment of peaceful bliss evoked by natural beauty" (Peterson \& Seligman 2004, P554). In the youth samples, gratitude has been significantly associated with positive affect, life satisfaction, optimism, social support and prosocial behaviour (Froh, Kashdan \& Yukewicz, 2009). 


\section{A Critical Overview of Research Studies on the Role of Positive Psychology Interventions in Enhancing Subjective Well-Being among High School Students}

An intervention conducted on sixth and seventh grades, based on counting blessings, had three groups: gratitude, hastle and control groups. In the gratitude group, students were asked to journal things they were grateful for. The hastle group were asked to journal five things that ignited or annoyed them. Post test results showed that students in the gratitude group displayed increased gratefulness, optimism and life satisfaction than the students in hastle or the control group.

3. Positive psychology intervention cultivates serenity among students. Serenity is a feeling of peacefulness, stillness and calm. Fredrickson (2009) lists serenity as one of the top ten positive emotions. Research evidence suggests that many students do not feel calm or peaceful when they are at school (Burehinal, Robert, Zeisel \& Rowky, 2008; Byrne, Davanport, \& Mazanor 2007; Granin 1992).

Research into the benefits of feeling serene shows that this emotion allows for insight generation, expanded attention, integration of thoughts and emotions, stress reduction and heightened compassion (Keegan, 2009; Levine, 2009; Theygeson, Hooke, Clapsadde Robbins, \& Moguist 2010).

One accepted technique of promoting positive emotion of serenity is meditation which is a process of paying attention, often to a particular object designated as a focus of concentration” (Campion \& Rocco, 2009).

Mindfulness is a state of internally and non-judgementally paying attention to the present moment (Kabat-Zinn, 1994; Broderick \& Melz, 2009). A study was conducted by holding six sessions of mindfulness training on students in a school as their health curriculum. They had divided the children into a training group and a control group. The training group showed increased feeling of calmness, relaxation and self acceptance and a decrease in negative affect than the control group after the intervention.

4. Positive psychology intervention develops resilience among students. Resilience is the ability and capacity to recuperate. It is positively linked with recovery from a set-back and stress as well as ability to reach out and seek new opportunities for growth (Reivich \& Shatter 2002).

Penn Resiliency Program (PRP) teaches cognitive repairing assertiveness, decision making, coping skills, creative brain-storming and relaxation. It has been used for students aged eight to fifteen years. Seventeen studies have been compared with PRP conducted and two thousand students reported reduced symptoms of depression, hopelessness and anxiety than the control group with significant improvements in well being. (Selignman 2009) . 


\section{A Critical Overview of Research Studies on the Role of Positive Psychology Interventions in Enhancing Subjective Well-Being among High School Students}

\section{Positive psychology intervention develops character strengths among students.}

Character strengths are defined as "pre-existing qualities that arise naturally, feel authentic, are intrinsically motivating to use, and energizing” (Brdar \& Kashdan, 2010). Character strengths of perservance, fairness, gratitude, honesty, hope and perspective were significant predicators of higher Grade Point Average (G.P.A) (Park \& Peterson, 2007).

Strathhaven Positive Psychology program developed in the USA is based on twenty four character strengths. VIA framework consist of twenty to twenty- five lessons to teach skills required for creating positive emotions and to allow students to identify and use their own character strengths.

Seligman evaluated the program and reported that there was improvement in the strengths related to love for learning and creativity but did not show any change in anxiety and depression.

Research has shown that college students with high hope levels have higher GPA and are more likely to graduate than those with low hope. When faced with challenges or obstacles in reaching their goals, those with higher hope levels have contingency plans and are willing to reach out for support to implement an alternative path toward their goal. (Grasgreen, 2012)

6. Positive psychology intervention increases life satisfaction. A research conducted by Sanghani Upadhya and Sharma (2013) at a centre for positive psychology in India focusing on improving positive emotions by P.P.I showed increase in their life satisfaction and parents reported a positive transformation in their wards.

Research also suggested a few good reasons that well-being should be taught in educational institutions namely the current flood of depression and the nominal increase in happiness and satisfaction over the last two generations. It would be an antidote to the runaway incidence of depression, a way to increase life satisfaction and an aid to better learning and more creative thinking. (Sanghani, Arya, Mare \& Ahuja, 2015)

\section{Critique}

Positive Psychology ignores the hedonic pursuit of pleasures. It seems like another guide for self-help optimism is a tool to help the individual achieve the goals he has set for himself (Seligman, 2006) but goals of social status and recognition may become illusionary (Miller, 2008).

Emotion is intentional and has an object. To illustrate, A is not simply angry but angry at someone. B is happy not simply but because he faired well in an exam. People feel different with different appraisal processes. Positive and Negative Emotions can co- exist as one can

(C) The International Journal of Indian Psychology, ISSN 2348-5396 (e)| ISSN: 2349-3429 (p) | 190 


\section{A Critical Overview of Research Studies on the Role of Positive Psychology Interventions in Enhancing Subjective Well-Being among High School Students}

experience positive emotions for a certain incident and negative for another. The positive emotion of play can reduce a person's capabilities in necessary actions like work. Excessive love tends to become attachment and cause of misery. Interest, if not maintained or persevered may result in diversity and superficial knowledge. Contentment may make an individual lazy and complacent. More empirical research is required to validate the promising effect of positive emotions. Sometimes positive emotions pose problems as in mania or if they are drug induced. Sensory pleasures motivate people to continue beyond normal which can result in problems of addiction if it is alcohol or drug related. People cannot maintain positive emotions all the time. The actual and real circumstances need to be taken into account. Positive emotions does play a very important role in subjective well being and life satisfaction.

The removal of negative factors is critical to well- being as well as fostering positive factors are important for flourishing and accomplishment. The Broaden and Build Effect of Positive Emotions states that positive affect accumulates and compounds over time, has the capacity to transform individuals to healthier, more socially engaged, integrated, and resilient beings.

\section{CONCLUSION}

Though Positive Psychology ignores the hedonic pursuit of pleasures as it is rooted in evolutionary and Humanistic Psychology and it seems like another guide for self-help, Positive emotions have the capacity to fuel flourishing which is a state of optimal human functioning, one that simultaneously implies growth and longevity, beauty and goodness, robustness and resilience and creativity and complexity (Keyes 2003; Fredrickson \& Losada, 2005).

Well-being, engagement and academic outcome are positively correlated. As Cummins (1996) has insightfully stated, "human relationships are the heart of schooling". The interactions that take place between students and teachers and among students are more central to their success than any method of teaching literature, science, or math. When powerful relationships are established between teachers and students, these relationships can frequently transcend the economic and social disadvantages that afflict communities and schools alike”. Teachers whom students see as supportive and who set clear expectations about behaviour help create an atmosphere in which students feel in control and confident about their ability to succeed in future educational endeavours.

Mental health promotion in schools is about providing a full continuum of mental health promotion programmes and services in schools. These include enhancing environments, promoting social and emotional learning and life skills, preventing emotional and behavioural problems, identifying problems and intervening early, and providing intervention for established problems (Weist and Murray, 2008). 


\section{A Critical Overview of Research Studies on the Role of Positive Psychology Interventions in Enhancing Subjective Well-Being among High School Students}

However, a core proponent of all conceptualizations of twenty first century schooling is the need for education to empower the student holistically in social, emotional, moral and intellectual aspects (Cain \& CarWaters, L., 2011). Positive psychology has great promise for the field of education.

This paper opens avenue for substantial longer duration work in schools for Positive Psychology Interventions which will encourage educators to include them in the academic curriculum.

\section{REFERENCES}

Anthony, E. J. (1987). Risk, Vulnerability, and resilience: An overview. In E. J. Anthony, \& B. J. Cohler, The invulnerable child. The Guilford psychiatry series (pp. 3-48). New York: Guilford Press.

Baron, R. A. (1976). The Control of Human Aggression: An incompatible Response Strategy.

Block, J., \& Kremen, A. M. (1996). IQ and Ego- Resiliency: Conceptual and Emperical Connections and Seperateness. Journal of Personality and Social Psychology , 70 (2), 349-361.

Campion, J., \& Rocco, S. (2009). Minding the Mind: The Effects and Potential of a SchoolBased Meditation Programme for Mental Health Promotion. Advances in School Menatl Health Promotion , 2 (1).

Cohler, B. J. (1987). Adversity, esilience, and the Study of Lives. In E. J. Anthony, \& B. J. Cohler, The Invulnerable Child (pp. 363-424). New York: Guilford Press.

Fielding, M. (2001). Students as Ragical Agents of Change. Journal of Educational Change , 123-141.

Fredrickson, B. L. (2004). The broaden- and- build theory of positive emotions. Philosophical Transactions of the Royal Society B: Biological Sciences , 359 (1449), 1367-1378.

Fredrickson, B. L., \& Branigan, C. (2005). Positive emotions broaden the scope of attention and thought-action repertoires. Cognition and Emotion , 19 (3), 313-332.

Fredrickson, B. L., \& Joiner, T. (2002). Positive Emotions Trigger Upward Spirals Toward Emotional Well-Being. Sage Journals , 13 (2), 172-175.

Fredrickson, B. L., \& Losada, M. F. (2005). Positive Affect and the Complex Dynamics of Human Flourishing. American Psychologist , 7, 678-686.

Frijda, N. H. (1986). The Emotions. Cambridge University Press.

Frijda, N. H., Kuipers, P., \& Schure, E. t. (1989). Relations Among Emotion, Appraisal, and Emotional Action Readiness. Journal of Personality and Social Psychology , 57 (2), 212228.

Jayanthi, P., Thirunavukarasu, M., \& Rajkumar, R. (2015). Academic Stress and Depression among Adolescents: A Cross - sectional Study. Indian Pediatrics , 52, 217-219.

Lazarus, R. S. (1991). Emotion and Adaptation. 


\section{A Critical Overview of Research Studies on the Role of Positive Psychology Interventions in Enhancing Subjective Well-Being among High School Students}

Malhotra, S., \& Patra, B. N. (2014). Prevalence of child and adolescent psychiatric disorders in India: a systematic review and meta-analysis. Child \&Adolescent Psychiatry \& Mental Health , 8 (22).

Marquez, S. C., Lopez, S. J., \& Pais- Ribeiro, J. L. (2011). "Building Hope for the Future": A Program to Foster Strengths in Middle- School Students. Journal of Happiness Studies , 139-152.

Murphy, L., \& Moriarty, A. (1976). Vulnerability, coping, and growth from infancy to adolescence. New Haven: University Press.

Onwuegbuzie, A. J., \& Snyder, C. R. (2000). Relations between hope and graduate students' coping strategies for studying and examination- taking. Psychological Reports , 86 (3.1), 803-806.

Sanghani, J., Upadhyay, U., \& Sharma, S. (2013). Positive Psychology intervention in education well- being and achievement. Journal of Positive Psychology , 251- 257.

Sin, N. L., \& Lyumbomirsky, S. (2009). Enhancing Well- Being and Alleviating Depressive Symptoms With Positive Psychology Interventions: A Practice Friendly Meta- Analysis. Journal of Clinicl Psychology , 65 (5), 467- 487.

Solomon, R. L., \& Corbit, J. D. (1978). An Opponent- Process Theory of Motivation. The American Economic Review , 68 (6), 12-24.

Tugade, M. M., \& Fredrickson, B. L. (2004). Resilient Individuals Use Positive Emotions to Bounce Back From Negative Emotional Experiences. Journal of Personal and Social Psychology , 86 (2), 320-333.

Verma, N., Jain, M., \& Roy, P. (2014). Assessment of Magnitude and Grades of Depression among Adolescents in Raipur City, India. International Research Journal of Medical Sciences , 2 (5), 10-13.

Waters, L. (2011). A review of school- based positive psychology interventions. The Australian Educational and Developmental Psychologist , 28 (2), 75-90.

Werner, E., \& Smith, R. S. (1992). Overcoming the Odds: High Risk Children from Birth to Adulthood. Cornell University Press .

Williams, S., \& Shiaw, W. T. (1999). Mood and Organizational Citizenship Behavior: The Effects of Positive Affect on Employee Organizational Citizenship Behavior Intentions. The Journal of Psychology: Interdisciplinary and Applied , 133 (6).

How to cite this article: J Sanghani, S Arya (2016), A Critical Overview of Research Studies on the Role of Positive Psychology Interventions in Enhancing Subjective Well-Being among High School Students, International Journal of Indian Psychology, Volume 3, Issue 3, No. 11, DIP: 18.01.209/20160303, ISBN: 978-1-365-21307-6

(c) The International Journal of Indian Psychology, ISSN 2348-5396 (e)| ISSN: 2349-3429 (p) | 193 